\title{
Optimal GROWTH AND IMPATIENCE: A PHASE DIAGRAM ANALYSIS
}

\author{
FWU-RANQ CHANG \\ CESIFO WORKING PAPER NO. 1359 \\ CAtegory 5: Fiscal Policy, Macroeconomics AND Growth \\ DECEMBER 2004
}

\footnotetext{
An electronic version of the paper may be downloaded

- from the SSRN website:

www.SSRN.com

- from the CESifo website:

www.CESifo.de
} 


\title{
OPTIMAL GROWTH AND IMPATIENCE: A PHASE DIAGRAM ANALYSIS
}

\begin{abstract}
In this paper we show that we can replace the assumption of constant discount rate in the onesector optimal growth model with the assumption of decreasing marginal impatience without losing major properties of the model. In particular, we show that the steady state exists, is unique, and has a saddle-point property. All we need is to assume that the discount function is strictly decreasing, strictly convex and has a uniformly bounded first-derivative.
\end{abstract}

JEL Code: C61, C62, O41.

Keywords: recursive utility, decreasing marginal impatience, saddle point, bounded slope assumption.

\author{
Fwu-Ranq Chang \\ Department of Economics \\ Indiana University \\ 100 S. Woodlawn \\ Bloomington, IN 47405 \\ USA \\ changf@indiana.edu
}

A draft of this paper was written in the summer of 2004 when I was a visiting research fellow at Economic Research Center (ERC) of Nagoya University, Japan. The paper was reported as ERC Discussion Paper No.151. I would like to thank ERC for its hospitality, its excellent research environment and its financial support, and Yuko Arayama for his help in various ways. I would also like to thank Bob Becker, Hess Chung and Sumit Joshi for their insightful comments and suggestions leading to the improvement of the paper. Naturally, all remaining errors are mine. 


\section{Introduction}

Since the seminal papers of Koopmans (1960) and Uzawa (1968), economists have broadened the class of dynamic preferences to include recursive utility functions to tackle the problems ${ }^{1}$ arising from the assumption of constant discount rate. Lucas and Stokey (1984) assumed increasing marginal impatience to ensure stability. Epstein (1987, pp.73-74) gave three reasons why employing the assumption of increasing marginal impatience is justified. Most studies, including the phase diagram analyses of the optimal growth models by Chang $(1994,2004)$ and Drugeon (1996), have focused on this increasing marginal impatience case.

The problems with decreasing marginal impatience are, as noted in Epstein (1983, p.140), that in deterministic models there exist many steady states and that some of them are locally unstable. The finding of "division of countries" by Magill and Nishimura (1984) is often cited as a reason to assume increasing marginal impatience. Specifically, Magill and Nishimura found that if the pure rate of time preference "decreases sufficiently rapidly"

\footnotetext{
${ }^{1}$ For example, Hicks (1965) argued that successive consumption units are supposed to be complementary, but an additively separable utility function implies that the marginal rate of substitution between lunch and supper is independent of the type of breakfast one had that morning or expects to have the next morning. See Wan (1970, p.274). In models with uncertainty, additive separability blurs the distinction between risk aversion and intertemporal substitution. See, for example, Epstein and Zin (1989) and Duffie and Epstein (1992). With additive separability, one would not care about the way in which consumption uncertainty resolves over time; whereas recursive utility permits nonindifference to the temporal resolution of uncertainty. See, Epstein and Zin (1989). Finally, additive separability has a peculiar long-run implication. Specifically, when there are heterogeneous agents, then, in the long run, the most patient consumer would own all the capital, while all other agents consume nothing and pay back their debts with all their labor income. See Becker (1980). For a comprehensive treatment on discrete time recursive utility theory, the reader is referred to Becker and Boyd (1997).
} 
(p.281), then there exists a critical level of capital that separates the rich countries from the poor countries in such a way that the poor countries remain at subsistence, while the rich countries have permanent development. This finding, however, raises a question: What would happen to growth theory if the decrement in the pure rate of time preference were uniformly bounded?

As pointed out in Lucas and Stokey (1984, p.169), the purpose of studying recursive utility is to see how far we can relax the assumption of convenience, namely the assumption of constant discount rate, without losing tractability. The question we shall address is this: Can we prove the existence, the uniqueness, and the saddle-point property of one-sector optimal growth with decreasing marginal impatience if the decrement in the discount function is uniformly bounded?

To this end, we assume that the discount function is strictly decreasing, strictly convex and that the slope of the discount function at zero consumption is bounded from below. Henceforth, the latter condition is referred to as the "bounded slope" assumption. Under this bounded slope assumption, while keeping the usual assumptions of preferences and technologies employed in the constant discount rate case, we show that the steady state of optimal growth with decreasing marginal impatience exists, is unique and the steady state has the usual saddle-point property.

The phase diagram analysis of the model can be summarized as follows. In the constant discount rate case, the curve corresponding to the steady state of consumption is a vertical line in the phase plane. In the decreasing marginal impatience case, the curve corresponding to the steady state of 
consumption is obtained from "bending" a vertical line into a smooth curve so that the upper part of the curve (relative to the steady state) is upward sloping and the lower part is downward sloping. The upper part of the curve is more like a bell-shaped curve than a C-shaped curve because it is asymptotic to another vertical line. This steady state retains all qualitative properties of the steady state in the constant discount rate case.

It is instructive to compare the stability analysis of the case of decreasing marginal impatience with that of increasing marginal impatience because the modeling differences between the two are in the discount function's derivatives. Borrowing the results from Chang (1994), we show that the phase diagram analyses of stability results in those two cases are "mirror images" of each other.

Given that the phase diagram analyses of two cases are "mirror images" of each other and that the constant discount rate case is the limit of either case, we present a diagram that contains all three cases. It makes clear the effects of the monotonicity of marginal impatience on the steady state consumption and steady state capital, in comparison with a constant discount rate. It also makes a clear statement about the stability analysis of monotonic marginal impatience and its saddle point property.

It should be mentioned that a phase diagram analysis of one-sector optimal growth model with decreasing marginal impatience has been made by Das (2003). She showed the existence and uniqueness of the steady state under a different stability condition. She also showed that the steady state is locally a saddle point by examining the characteristic roots of the dynamic system. Unfortunately, her phase diagram analysis contains an error and is 
incomplete; her stability assumption would actually impose some additional restrictions for the growth model. Comments on Das (2003) are presented in Section 3.4.

\section{The Model}

The model of optimal growth with decreasing marginal impatience is similar to the model with increasing marginal impatience of Chang (1994). We shall follow its framework and notation as closely as possible for easy reference and comparison of these two cases.

The law of motion is the standard Solow equation

$$
\dot{k}=f(k)-c-n k .
$$

The per capita production function $f(k)$ is assumed to be of class $C^{2}$ (twice continuously differentiable), strictly increasing, strictly concave, satisfying the Inada conditions:

$$
f(0)=0, \lim _{k \rightarrow 0} f^{\prime}(k)=\infty, \text { and } \lim _{k \rightarrow \infty} f^{\prime}(k)=0 .
$$

The objective function is

$$
\int_{0}^{\infty} D(t) U\left(c_{t}\right) d t
$$

where $U(c)$ is the instantaneous utility function, which is of class $C^{2}$, strictly increasing and strictly concave in $c$, and

$$
D(t)=\exp \left\{-\int_{0}^{t} \delta\left(c_{s}\right) d s\right\}, \delta\left(c_{s}\right)>0,
$$

is the discount factor at time $t$. We shall refer to $\delta(c)$ as the (instantaneous) discount function, which is also of class $C^{2}$. 
Clearly, $D(t)$ assumes values in $(0,1]$, depends on the underlying consumption path $\left\{c_{s}: s \leq t\right\}$, and is decreasing in time because

$$
D^{\prime}(t)=-D(t) \delta\left(c_{t}\right)<0 .
$$

By definition, $D(0)=1$ and $D^{\prime}(0)=-\delta\left(c_{0}\right)<0$. In the classic case of a constant discount rate, i.e., $\delta\left(c_{t}\right)=\delta$, where $\delta$ is a constant, we have $D(t)=e^{-\delta t}$ with $D^{\prime}(t)=-D(t) \delta$.

What distinguishes the case of increasing marginal impatience from the case of decreasing marginal impatience is the functional structure of $\delta(c)$. By increasing marginal impatience we mean $\delta^{\prime}(c)>0$, and by decreasing marginal impatience we mean $\delta^{\prime}(c)<0$. In the case of decreasing marginal impatience, we also assume $\delta(0)=b>0$ and $\delta^{\prime \prime}(c)>0$. That is, $\delta(c)$ is strictly decreasing and strictly convex in $c \geq 0$. We also assume that $\delta(c)$ is asymptotic to the horizontal axis $\delta=0$ so that

$$
0<\delta(c) \leq b .
$$

Then the optimal growth problem with decreasing marginal impatience is formulated as

$$
\max _{\{c t\}}(2) \text {, s.t. (1). }
$$

It is standard to verify that the value function of (5), in current value form, is independent of the initial time, and depends only on the initial capital-labor ratio. Henceforth, we denote it by $J(k)$. For the moment, we assume $U(c) \geq 0$ so that $J(k) \geq 0$; the case $U(c)<0$ will be discussed later. The Bellman equation for problem (5) is ${ }^{2}$

$$
0=\max _{c}\left\{U(c)-\delta(c) J(k)+[f(k)-c-n k] J^{\prime}(k)\right\} .
$$

\footnotetext{
${ }^{2}$ The method of deriving the Bellman equation, the costate equation, and the Euler
} 
The first-order condition of (6) is

$$
U^{\prime}(c)-\delta^{\prime}(c) J(k)-J^{\prime}(k)=0
$$

and the second order sufficient condition is

$$
U^{\prime \prime}(c)-\delta^{\prime \prime}(c) J(k)<0
$$

The second order condition (8) is clearly satisfied because $J(k) \geq 0$. It follows that the optimal consumption $c=c(k)$ is a function of $k$ by the implicit function theorem.

Let the costate variable be $p=J^{\prime}(k)$, which is the shadow price of $k$. This shadow price

$$
p=U^{\prime}(c)-\delta^{\prime}(c) J(k)
$$

is clearly positive since $J(k) \geq 0$. Then, the costate equation is

$$
\dot{p}=-p\left[f^{\prime}(k)-n-\delta(c)\right] .
$$

Substituting (9) into (10), we have the Euler equation

$$
\sigma(k, c) \dot{c}=f^{\prime}(k)-n-\delta(c)-\delta^{\prime}(c)[f(k)-c-n k],
$$

where

$$
\sigma(k, c)=-\frac{U^{\prime \prime}(c)-\delta^{\prime \prime}(c) J(k)}{U^{\prime}(c)-\delta^{\prime}(c) J(k)}
$$

The numerator of $\sigma(k, c)$ is negative by the second order sufficient condition (8). The denominator of $\sigma(k, c)$ is the shadow price $p$, which is positive. Therefore, $\sigma(k, c)>0$ for all $(k, c)$ and the Euler equation (11) is nondegenerate. Notice that the sign of $\dot{c}$ is independent of the utility function $U(c)$.

equation is standard in the literature. See, for example, Chang $(1994,2004)$. The stochastic version of the Bellman equation for this class of objective functions is derived in Krylov (1980, p.25) and Chang (2004). 


\section{$3 \quad$ Stability Analysis}

Let $\bar{k}$ be the maximal sustainable capital-labor ratio, i.e., $f(\bar{k})=n \bar{k}$. We can therefore restrict our discussion to the compact interval $[0, \bar{k}]$. Let

$$
k_{1}=\left(f^{\prime}\right)^{-1}(n+b)=\left(f^{\prime}\right)^{-1}(n+\delta(0)) \text {, }
$$

and

$$
k_{2}=\left(f^{\prime}\right)^{-1}(n)=\left(f^{\prime}\right)^{-1}\left(n+\lim _{c \rightarrow \infty} \delta(c)\right) .
$$

Since $b>0$, we have $k_{1}<k_{2}$.

Bounded slope assumption. Assume

$$
0<-\delta^{\prime}(0) \leq\left(\frac{1}{b}\right) \min _{k \in\left[k_{1}, k_{2}\right]}\left[-f^{\prime \prime}(k)\right] .
$$

The interval $\left[k_{1}, k_{2}\right]$ is a compact set and therefore the minimum exists and is finite. From the definitions of $k_{1}$ and $k_{2}$ we note that the upper bound of $-\delta^{\prime}(0)$ is given by the exogenous parameters such as population growth rate $n$, a preference condition $(\delta(0)=b)$, the production technology $f(k)$, and nothing else. In other words, the upper bound of $-\delta^{\prime}(0)$ is the joint restriction on preferences and technology. If $f^{\prime \prime}(k)$ is monotonic $\left(f^{\prime \prime \prime}(k)>0\right.$ or $\left.f^{\prime \prime \prime}(k)<0\right)$, then $\min _{k \in\left[k_{1}, k_{2}\right]}\left[-f^{\prime \prime}(k)\right]$ is simplified to $\min \left\{-f^{\prime \prime}\left(k_{1}\right),-f^{\prime \prime}\left(k_{2}\right)\right\}$.

The economic intuition of the bounded slope assumption is quite obvious. While going from zero consumption to a positive consumption would decrease the discount function, the decrement would not be unduly steep. In particular, it rules out the possibility of $\delta^{\prime}(0)=-\infty$. Since $\delta(c)$ is strictly decreasing and strictly convex in $c$, the same upper bound applies to all $-\delta^{\prime}(c)$, and hence $\delta^{\prime}(c)$ is uniformly bounded. In other words, the discount 
function can never decrease "sufficiently rapidly" at any consumption level $c$.

\subsection{Steady State}

The steady state of the pair of equations (1) and (11), if it exists, is denoted by $\left(k_{d}, c_{d}\right)$. By definition, $\left(k_{d}, c_{d}\right)$ satisfies $\dot{k}=\dot{c}=0$, i.e.,

$$
f(k)-c-n k=0,
$$

and

$$
f^{\prime}(k)-n-\delta(c)=0 .
$$

The curve defined by (12), denoted by $L_{1}$, is of inverted "U" shape with $k$-axis intercepts 0 and $\bar{k}$, which is the same as the constant discount rate case (and increasing marginal impatience case as well).

The curve defined by (13), denoted by $L_{2}$, is upward sloping, i.e.,

$$
\frac{d c}{d k}=\frac{f^{\prime \prime}(k)}{\delta^{\prime}(c)}>0,
$$

because $f^{\prime \prime}(k)<0$ and $\delta^{\prime}(c)<0$. The $k$-axis intercept $(c=0)$ of the curve $L_{2}$ is $k_{1}$. This means that $L_{2}$ is not defined for $k<k_{1}$ because $\delta(c) \leq b$. For $k \geq k_{2}$, we have $f^{\prime}(k)-n \leq 0$, which implies that $\delta(c) \leq 0$ if (13) is satisfied. In other words, $L_{2}$ is not defined on $k \geq k_{2}$ either. In summary, $L_{2}$ is defined only on $\left[k_{1}, k_{2}\right)$, and on which $0<f^{\prime}(k)-n \leq b$.

As $k$ approaches $k_{2}$ from the left, $f^{\prime}(k) \rightarrow n$. Along the curve $L_{2}, \delta(c)=$ $f^{\prime}(k)-n \rightarrow 0$, and therefore, $c \rightarrow \infty$. This observation says that $L_{2}$ is asymptotic to the vertical line $k=k_{2}$. This asymptotic property implies that the curve $L_{2}$ must cross $L_{1}$ at least once, i.e., a steady state always exists. 
To show the uniqueness of the steady state, it suffices to show that the two curves $L_{1}$ and $L_{2}$ cross each other only once. Since $0<f^{\prime}(k)-n \leq b$ on $\left[k_{1}, k_{2}\right)$, we have, for any $c$,

$$
-\delta^{\prime}(c)\left[f^{\prime}(k)-n\right] \leq-\delta^{\prime}(c) b, \text { for all } k \in\left[k_{1}, k_{2}\right) .
$$

The above inequality remains valid for $k=k_{2}$ because $f^{\prime}\left(k_{2}\right)=n$. On the other hand, for any $c>0$,

$$
-\delta^{\prime}(c) b<-\delta^{\prime}(0) b,
$$

because $\delta^{\prime}(c)<0$ and $\delta^{\prime \prime}(c)>0$. Then the bounded slope assumption implies that, for any $c>0$,

$$
-\delta^{\prime}(c)\left[f^{\prime}(k)-n\right]<-f^{\prime \prime}(k), \text { for all } k \in\left[k_{1}, k_{2}\right] .
$$

Since (14) is valid for all $c>0$, it is valid when $c=\delta^{-1}\left(f^{\prime}(k)-n\right)$ with $k \in\left[k_{1}, k_{2}\right)$, i.e., as we move along $L_{2}$. In this case, we have

$$
f^{\prime}(k)-n<\frac{f^{\prime \prime}(k)}{\delta^{\prime}\left(\delta^{-1}\left(f^{\prime}(k)-n\right)\right)} .
$$

This inequality says that the slope of the curve $L_{2}, f^{\prime \prime}(k) / \delta^{\prime}(c)$, is strictly greater than the slope of the curve $L_{1}, f^{\prime}(k)-n$, at any point in the interval $\left[k_{1}, k_{2}\right)$. This makes the second crossing (including tangency) of the two curves impossible.

The unique intersection of the two curves $L_{1}$ and $L_{2}$ defines the steady state $\left(k_{d}, c_{d}\right)$, where $k_{d} \in\left(k_{1}, k_{2}\right)$. That is, the steady state is in the increasing section of the $L_{1}$ curve. See Figure 1. In summary, we have

Proposition 1 Under the bounded slope assumption, the steady state of optimal growth with decreasing marginal impatience exists and is unique. 


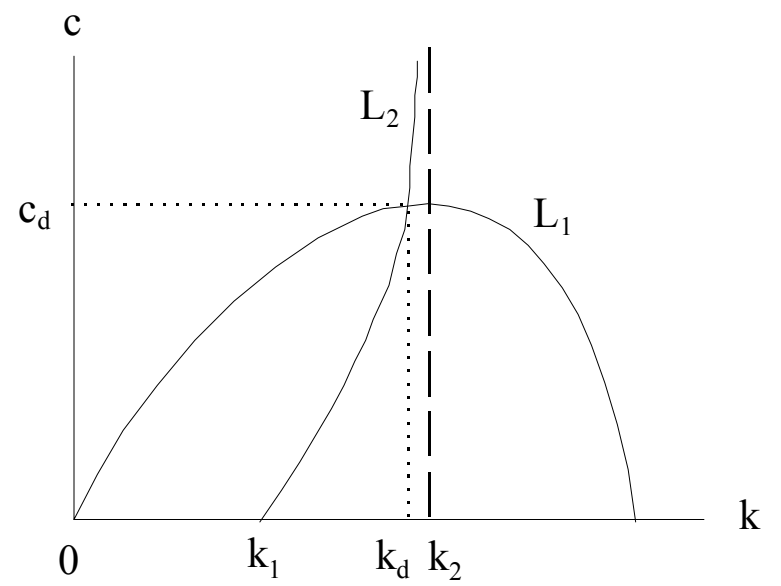

Figure 1: Existence and uniqueness of the steady state

Some comparative dynamics can easily be obtained. A decrease in the population growth rate, $n$, "expands" the curve $L_{1}$ and shifts the curve $L_{2}$ to the right as shown in Figure 2. Steady state consumption and capital are unambiguously increased. This result is quite intuitive because there are simply fewer people to feed and to share the existing capital. Similarly, an increase in Hicks-neutral technical progress, i.e., a shift of the production function from $A f(k), A=1$, to $A f(k), A>1$, would also expand the curve $L_{1}$ and shifts the curve $L_{2}$ to the right as shown in Figure 2. Again, steady state consumption and capital are unambiguously increased. This is also quite intuitive because such a technological change represents a scale effect on production and hence on consumption. In both cases, the results resemble the comparative dynamics of the optimal growth model with a 


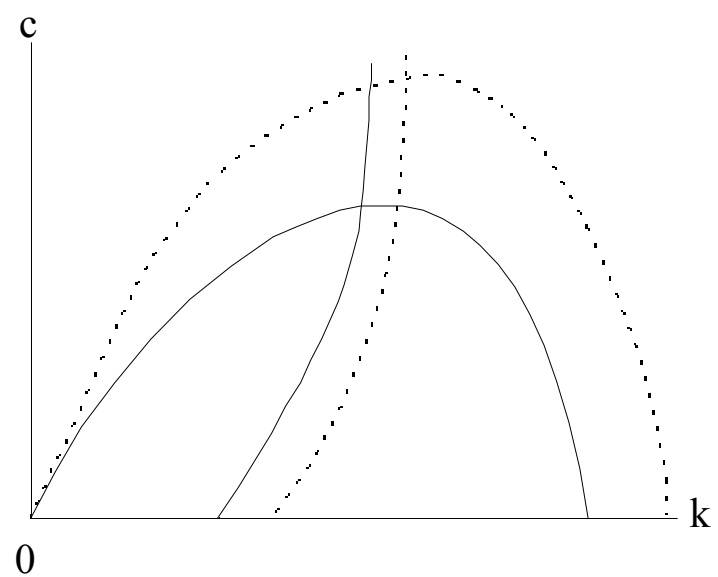

Figure 2: Comparative Dynamics

constant discount rate.

\subsection{Phase Diagram}

Let the curve defined by $\dot{c}=0$ be $L_{3}: R(k, c)=0$, where

$$
R(k, c)=f^{\prime}(k)-n-\delta(c)-\delta^{\prime}(c)[f(k)-c-n k]
$$

The location of the curve $L_{3}$ can be determined as follows. First, we recognize that $L_{1}$ and $L_{2}$ divide the first quadrant of the $(k, c)$-plane into four sectors: $\mathrm{A}, \mathrm{B}, \mathrm{C}$, and D. See Figure 3. In sector B we have $R(k, c)<0$, because it is the region above the curve $L_{1}$ (i.e., $f(k)-c-n k<0$ ) and below (or to the right of) the curve $L_{2}$ (i.e., $\left.f^{\prime}(k)-n-\delta(c)<0\right)$. Therefore, the curve $L_{3}: R(k, c)=0$ cannot lie in this sector. Similarly, in sector $\mathrm{C}$ we have $R(k, c)>0$, because it is the region below the curve $L_{1}$ (i.e., $f(k)-c-n k>$ 


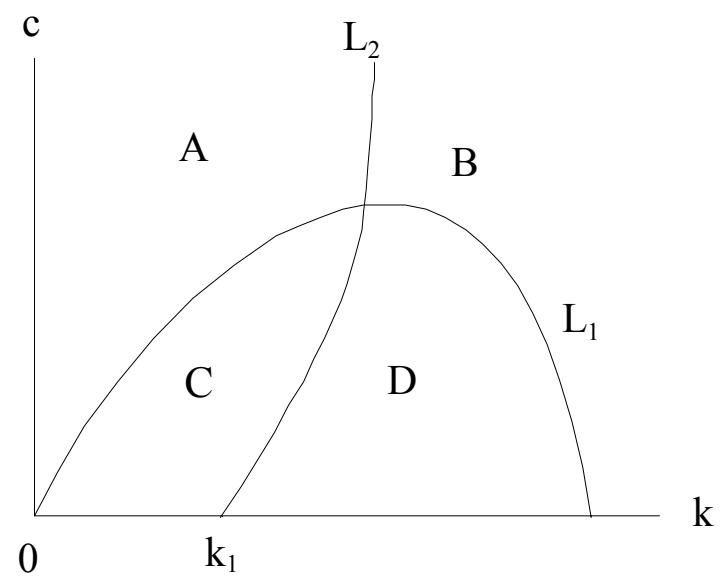

Figure 3: The curve $L_{3}$ lies in region $\mathrm{A}$ and region $\mathrm{D}$.

0 ) and above (or to the left of) the curve $L_{2}$ (i.e., $f^{\prime}(k)-n-\delta(c)>0$ ). Again, the curve $L_{3}: R(k, c)=0$ cannot lie in this sector. Therefore, the curve $L_{3}: R(k, c)=0$ must be located in sector A (above $L_{1}$ and $L_{2}$ ) and sector $\mathrm{D}$ (below $L_{1}$ and $L_{2}$ ). When $L_{3}$ is in sector $\mathrm{A}$, we have $k<k_{2}$. Similarly, when $L_{3}$ is in sector $\mathrm{D}$, we have $k_{1}<k<\bar{k}$.

Next, we examine the behavior of the curve $L_{3}$ in the strip $S$ defined by

$$
S=\left\{(k, c): k \in\left[k_{1}, k_{2}\right]\right\}
$$

For all $(k, c) \in S$, we have

$$
R_{k}(k, c)=f^{\prime \prime}(k)-\delta^{\prime}(c)\left[f^{\prime}(k)-n\right]<0
$$

using (14). Applying the implicit function theorem to the curve $L_{3}: R(k, c)=$ 
$0, k$ can be written as a function of $c$, which has a derivative

$$
\frac{d k}{d c}=-\frac{R_{c}}{R_{k}}=\frac{\delta^{\prime \prime}(c)[f(k)-c-n k]}{f^{\prime \prime}(k)-\delta^{\prime}(c)\left[f^{\prime}(k)-n\right]} .
$$

Note that the implicit function theorem applies to all points of $R(k, c)=0$ in $S$. Inequality (14) implies that the denominator of (16) is negative on $S$. Then the sign of $d k / d c$ depends only on the sign of the numerator of (16). Since $\delta^{\prime \prime}(c)>0, d k / d c$ has a sign opposite of $\dot{k}$.

If $(k, c)$ lies above $L_{1}$, i.e., $f(k)-c-n k<0$, then $\dot{k}<0$ and hence $k$ is increasing in $c$. Similarly, if $(k, c)$ lies below $L_{1}, k$ is decreasing in $c$. At $\left(k_{d}, c_{d}\right), d k / d c$ equals zero. Thus, the curve $L_{3}$ in the strip $S$ can be obtained from "bending" the vertical line $k=k_{d}$ into a smooth curve so that the upper part of the curve (above $\left(k_{d}, c_{d}\right)$ ) is upward sloping and the lower part is downward sloping. See Figure 4. Using the expression of a "C-shaped" curve for $L_{3}$ would be misleading because the upper part of $L_{3}$ is asymptotic to another vertical line $k=k_{2}$; a bell-shaped curve would be a better description of the upper part of $L_{3}$. Moreover, the upper part of $L_{3}$ stays in the strip $\left\{(k, c): k_{d} \leq k \leq k_{2}\right\}$, which is smaller than $S$.

If the lower portion of $L_{3}$ stays in $S$, then the description of $L_{3}$ is complete. If it extends to the region $\left[k_{2}, \bar{k}\right]$, the curve is still downward sloping. This is because in this region, $f^{\prime}(k) \leq n$, which implies $R_{k}(k, c)<0$, and the implicit function theorem is still applicable. In any event, the lower part of $L_{3}$ stays in the strip $\left\{(k, c): k_{d} \leq k \leq \bar{k}\right\}$.

Now we are ready to determine the vertical arrows of the phase diagram. Since $R_{k}(k, c)<0$ on $\left[k_{1}, k_{2}\right], R(k, c)>0$ in the region to the left of $L_{3}$. Hence, $\dot{c}>0$ in the region to the left of $L_{3}$. Similarly, $\dot{c}<0$ in the region to 


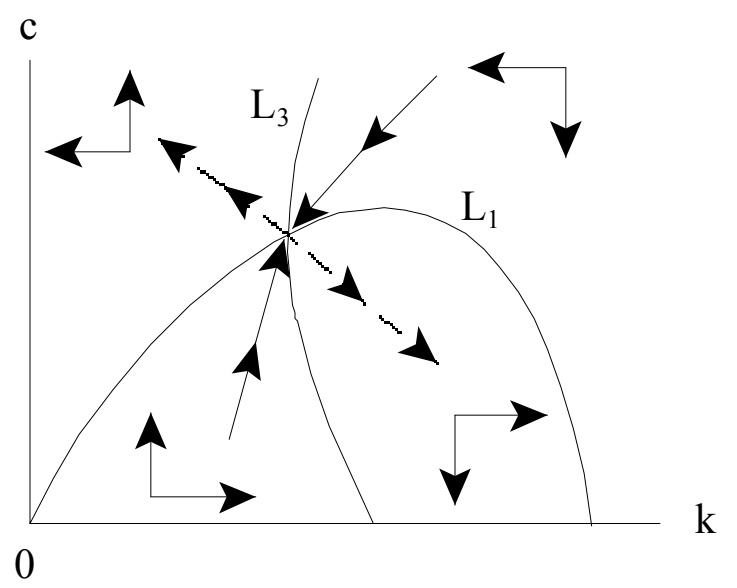

Figure 4: The steady state is a saddle point

the right of $L_{3}$. In summary, the vertical arrows are as follows:

$$
\begin{aligned}
& \dot{c}<0 \text { if }(k, c) \text { is to the right of } L_{3} ; \\
& \dot{c}>0 \text { if }(k, c) \text { is to the left of } L_{3} .
\end{aligned}
$$

The horizontal arrows are the same as the constant discount rate case, i.e.,

$$
\begin{aligned}
& \dot{k}<0 \text { if }(k, c) \text { is above the curve } L_{1} ; \\
& \dot{k}>0 \text { if }(k, c) \text { is below the curve } L_{1} .
\end{aligned}
$$

Combining all arrows, a complete phase diagram is shown in Figure 4.

The linearized system of equations of the nonlinear system (1) and (11), using the facts that $f^{\prime}\left(k_{d}\right)-n=\delta\left(c_{d}\right)$ and $R_{c}\left(k_{d}, c_{d}\right)=0$, is

$$
\left[\begin{array}{c}
\dot{k} \\
\dot{c}
\end{array}\right]=\left[\begin{array}{cc}
\delta\left(c_{d}\right) & -1 \\
\phi\left(k_{d}, c_{d}\right) & 0
\end{array}\right]\left[\begin{array}{c}
k-k_{d} \\
c-c_{d}
\end{array}\right],
$$


where

$$
\phi\left(k_{d}, c_{d}\right)=\frac{f^{\prime \prime}\left(k_{d}\right)-\delta^{\prime}\left(c_{d}\right)\left[f^{\prime}\left(k_{d}\right)-n\right]}{\sigma\left(k_{d}, c_{d}\right)} .
$$

(The method of linearization in stability analysis is standard. See, for example, Brock and Malliaris (1989).) The characteristic equation of the linearized system is

$$
\lambda^{2}-\delta\left(c_{d}\right) \lambda+\phi\left(k_{d}, c_{d}\right)=0
$$

Since $R_{k}(k, c)<0$ on the strip $S$, and $\sigma(k, c)>0$, we have $\phi\left(k_{d}, c_{d}\right)<0$. It implies that the discriminant of the characteristic equation is positive $\left(\left[\delta\left(c_{d}\right)\right]^{2}-4 \phi\left(k_{d}, c_{d}\right)>0\right)$ and the product of the characteristic roots is negative. Thus, the two characteristic roots are real and opposite in sign, and the steady state is a saddle point. Such a steady state is unstable; however, as shown in Figure 4, there is a stable branch converging to $\left(k_{d}, c_{d}\right)$ and an unstable branch diverging from it.

Proposition 2 The steady state of the optimal growth model with decreasing marginal impatience is a saddle point.

\subsection{The case of $U(c)<0$}

If $U(c)<0$, then $J(k)<0$. In this case we need to assume that the second order sufficient condition (8) is valid and that

$$
-\frac{\delta^{\prime \prime}(c)}{\delta^{\prime}(c)} \geq-\frac{U^{\prime \prime}(c)}{U^{\prime}(c)} .
$$

The inequality (17) says that the degree of convexity of $\delta(c)$ is greater than the degree of concavity of $U(c)$. Then the shadow price of capital-labor ratio 
satisfies

$$
\begin{aligned}
p & =U^{\prime}(c)-\delta^{\prime}(c) J(k)=U^{\prime}(c)\left[1-\frac{\delta^{\prime}(c)}{U^{\prime}(c)} J(k)\right] \\
& \geq U^{\prime}(c)\left[1-\frac{\delta^{\prime \prime}(c)}{U^{\prime \prime}(c)} J(k)\right]=\frac{U^{\prime}(c)}{U^{\prime \prime}(c)}\left[U^{\prime \prime}(c)-\delta^{\prime \prime}(c) J(k)\right]>0,
\end{aligned}
$$

the last inequality is obtained from (8). It is then straightforward to verify that the properties such as the existence, the uniqueness, and the saddle point property of the steady state remain valid.

It is interesting to point out that, in the case of increasing marginal impatience, (8) and $p>0$ are automatic if $U(c)<0$. But assumptions (8) and (17) are required for $p>0$ if $U(c) \geq 0$. In that case, assumption (17) simply says that $\delta(c)$ is more concave than $U(c)$. See Chang (1994) and Drugeon (1996) for details.

\subsection{Comments on Das (2003)}

As mentioned before, Das (2003) has made great stride in analyzing the optimal growth with decreasing marginal impatience. She showed the existence and uniqueness of the steady state under the following inequality

$$
-f^{\prime \prime}(k)>-\delta^{\prime}(f(k)-n k)\left[f^{\prime}(k)-n\right], \text { for all } k \in\left(0, k_{2}\right]
$$

She also showed that the steady state is locally a saddle point by verifying the two characteristic roots are opposite in sign. Many equations in Das (2003) bear a close resemblance to our equations. For example, the costate equation (10) corresponds to her equation (12). Euler equation (11) corresponds to her equation (15) [after applying her equation (23)]. Equation (16) that 
determines the steady state consumption curve $\dot{c}=0$ is the reciprocal of her equation (A.23).

But there are problems in her analysis. The domain of $(18)$ is $\left(0, k_{2}\right]$. As $k \rightarrow 0$, we have $f^{\prime}(k) \rightarrow \infty$ and inequality (18) may fail. Similarly, inequality (18) may fail if $\delta^{\prime}(0)$ is unbounded. Imposing conditions on $f^{\prime \prime}(k)$, as $k \rightarrow 0$, to tackle the aforementioned problems would not relax assumptions imposed for analytical convenience. In contrast, we do not have this problem because our bounded slope assumption is defined on an interval $\left[k_{1}, k_{2}\right]$ away from $k=0$. We also think that our bounded slope condition is intuitively appealing.

More importantly, there is an error in Das's (2003) stability analysis. To elaborate, let

$$
g(k, c)=f^{\prime \prime}(k)-\delta^{\prime}(c)\left[f^{\prime}(k)-n\right] .
$$

Inequality (18) is obtained by substituting $c=c(k)=f(k)-n k$ into (19) so that $(18)$ can be written as $g(k, c(k))<0$. In so doing, the inequality (18) is a condition along the curve $L_{1}: c=f(k)-n k$, in the $(k, c)$-plane. Assumption (18) ensures

$$
g\left(k_{d}, c_{d}\right)=f^{\prime \prime}\left(k_{d}\right)-\delta^{\prime}\left(c_{d}\right)\left[f^{\prime}\left(k_{d}\right)-n\right]<0
$$

so that $d k / d c$ is zero at $\left(k_{d}, c_{d}\right)$. What Professor Das failed to recognize is that the function $g(k, c)$ is continuous in the $(k, c)$-plane because $f(k)$ and $\delta(c)$ are of class $C^{2}$. By continuity, if $g\left(k_{d}, c_{d}\right)<0$, then we must have $g(k, c)<0$, i.e.,

$$
f^{\prime \prime}(k)-\delta^{\prime}(c)\left[f^{\prime}(k)-n\right]<0
$$

in some neighborhood of $\left(k_{d}, c_{d}\right)$. Therefore it is impossible for the denomi- 
nator of (16) to change signs in that same neighborhood of $\left(k_{d}, c_{d}\right)$. Instead, Professor Das argued that the sign of the denominator of (16) is ambiguous. This error led Professor Das to draw the conclusion that the curve $L_{3}$ may be of "S" shape as represented by her Figure 3. Professor Das's description of the $L_{3}$ curve, and therefore the corresponding stability analysis, is incomplete.

In addition, Das (2003) studied only the case with $U(c)>0$; our stability results, however, apply to growth models with decreasing marginal impatience whether $U(c)>0$ or $U(c)<0$. We are able to do this because we take the dynamic programming approach. As pointed out by Drugeon (1996, p.284), dynamic programming method is appealing because "it allows for a simplified analysis of the optimal path over the plane."

\section{All Cases Considered}

It would be useful and instructive to compare all cases (decreasing marginal impatience, constant marginal impatience, and increasing marginal impatience) in a single framework and in the same diagram. To this end, we borrow from Chang (1994) the results of the case of increasing marginal impatience in which $\delta(c)>0, \delta^{\prime}(c)>0$ and $\delta^{\prime \prime}(c)<0$.

The curve defined by (13), denoted by $L_{4}$, is downward sloping, $d c / d k<$ 0 , due to $f^{\prime \prime}(k)<0$ and $\delta^{\prime}(c)>0$. Its $k$-axis intercept is

$$
k_{3}=\left(f^{\prime}\right)^{-1}(n+\delta(0))<\left(f^{\prime}\right)^{-1}(n)=k_{2} .
$$

Therefore, the curve $L_{4}$ intersects the curve $L_{1}$ at its upward sloping portion and the intersection is unique. Denote it by $\left(k_{i}, c_{i}\right)$. See Figure 5 . Notice 


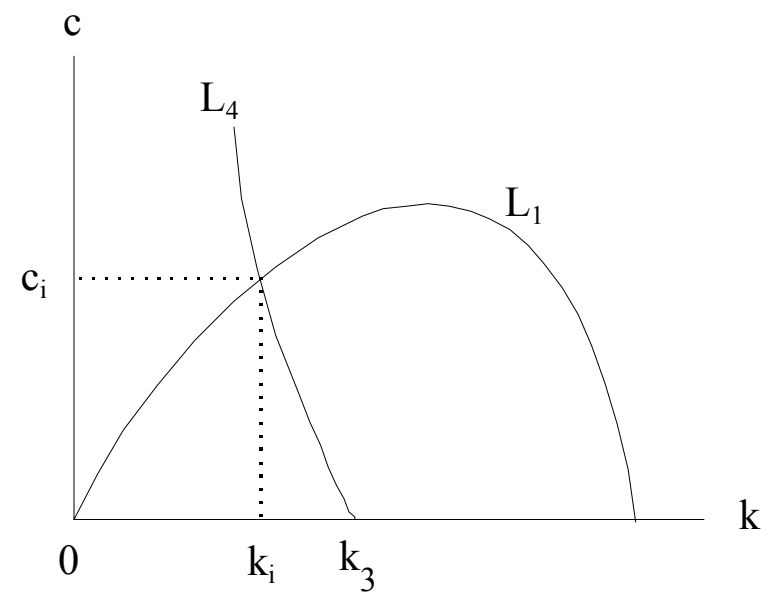

Figure 5: Existence and uniqueness of the steady state (increasing marginal impatience)

that, unlike the decreasing marginal impatience case, the steady state $\left(k_{i}, c_{i}\right)$ is uniquely determined without a bounded slope assumption.

The curves $L_{1}$ and $L_{4}$ partition the first quadrant of the $(k, c)$-plane into four sectors. It can be verified that the curve $L_{5}: R(k, c)=0$ is located in sector B that is above the curve $L_{1}$ and to the right of $L_{4}$, and in sector $\mathrm{C}$ that is below the curve $L_{1}$ and to the left of the curve $L_{4}$. See Figure 6 .

The phase diagram can be obtained similarly. Let the curve defined by $\dot{c}=0$ be $L_{5}: R(k, c)=0$, where $R(k, c)$ is defined in (15). It is shown in Chang (1994), using the strict concavity of $\delta(c)$, that $R(k, c)<0$ on $\left[k_{2}, \bar{k}\right]$ for any $c$. Therefore, the location of the curve $L_{5}$ is in the strip

$$
\left\{(k, c): k \in\left[0, k_{2}\right]\right\}
$$




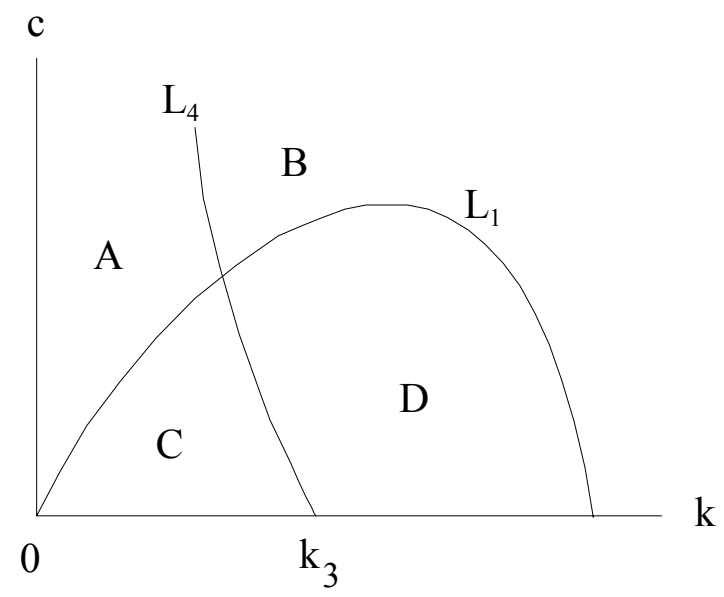

Figure 6: The curve $L_{5}$ lies in sector B and C

In this strip, $f^{\prime \prime}(k)-\delta^{\prime}(c)\left[f^{\prime}(k)-n\right]<0$, i.e., (14) is always satisfied. Notice that we do not need to assume a bounded slope condition in this case. The phase diagram of optimal growth with increasing marginal impatience is drawn in Figure 7.

The case of constant impatience $\delta(c)=\delta$ is well-known. See, for example, Intriligator (1971). In that case, the curve associated with $\dot{c}=0$ (or $f^{\prime}(k)-$ $n-\delta=0)$ is a vertical line, $k=k_{0}$, where

$$
k_{0}=f^{-1}(n+\delta) .
$$

The phase diagram is reproduced in Figure 8.

To make meaningful connections among the three cases, we have to relate the constant $\delta$ in the constant discount rate case to $\delta(0)$ in the other two cases. In the increasing marginal impatience case, we assume $\delta(0)=\delta$ (i.e., 


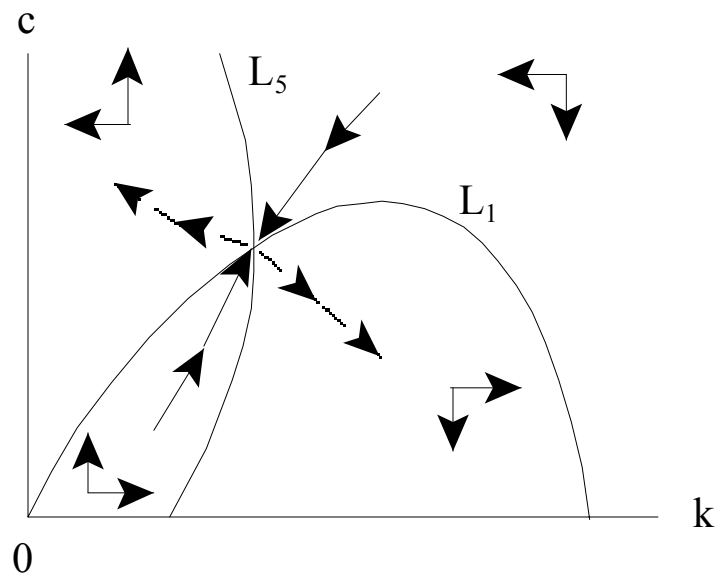

Figure 7: The steady state is a saddle point (increasing marginal impatience)

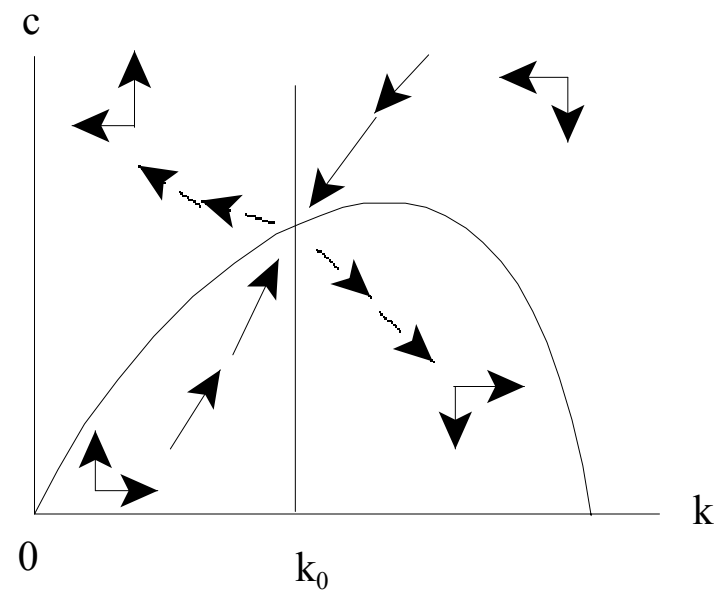

Figure 8: The phase diagram of constant discount rate case 


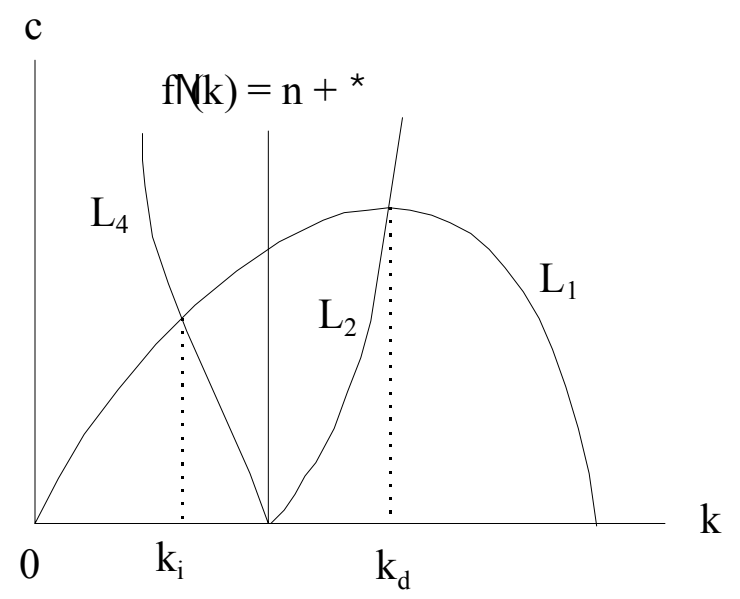

Figure 9: Comparison of the location of the steady states

$\left.k_{0}=k_{3}\right)$ so that $\delta(c)>\delta$ for all $c>0$. In the decreasing marginal impatience case, we assume $\delta(0)=b=\delta$ (i.e., $k_{0}=k_{1}$ ) so that $\delta(c)<\delta$ for all $c>0$. Treated this way, the constant discount rate becomes the limiting case of both decreasing and increasing marginal impatience growth models. Figure 9 shows the relative position of the steady states among the three cases.

Figure 10 shows that the effect of changing from constant marginal impatience to monotonic marginal impatience is simply to "shift and bend" the vertical line $k=k_{0}$; the rest of the stability analysis essentially remains unchanged. 


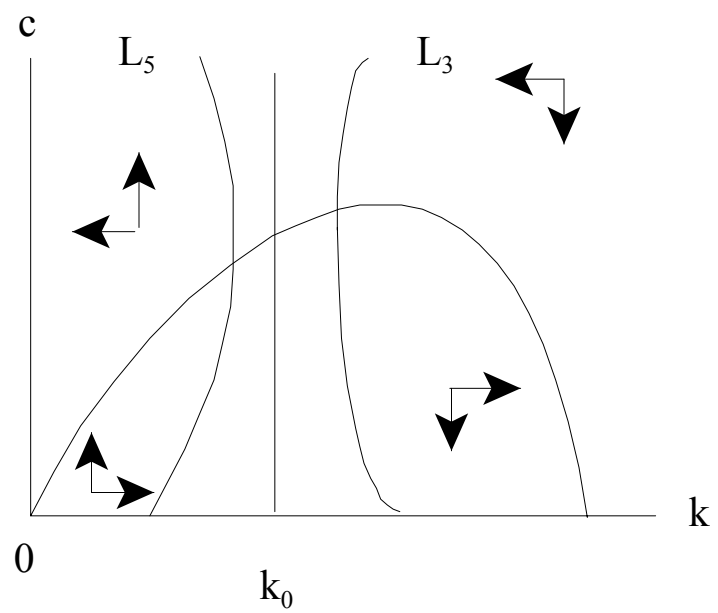

Figure 10: To change from constant marginal impatience to non-constant one is to bend the vertical line $k=k_{0}$

\section{Concluding Remarks}

In this paper we show that we can replace the assumption of constant discount rate in the one-sector growth model with decreasing marginal impatience without losing any major properties of the model. In particular, the major properties such as the existence, the uniqueness, and the saddle point property of the steady state remain valid. All we need is to assume that the discount function is convex and has a uniformly bounded first-derivative.

We also show that the phase diagram analysis of the optimal growth with decreasing marginal impatience is a "mirror image" of the phase diagram analysis of the optimal growth with increasing marginal impatience, and that the constant discount rate case can be regarded as the limiting case of 
either model. All three cases are qualitatively equivalent under reasonable assumptions. From this perspective, the assumption of constant discount rate is more of a restriction than convenience, at least for the continuoustime one-sector optimal growth model.

The bounded slope assumption is closely related to the work of Magill and Nishimura (1984). However, it is not always true that continuous-time results would automatically imply discrete-time ones, nor the converse. See Chang $(1988,2004)$ for discussion. The effects of the bounded slope assumption on the discrete time models remain to be investigated. This is for future research. 


\section{References}

[1] Becker, Robert (1980), "On the Long-Run Steady State in a Simple Dynamic Model of Equilibrium with Heterogeneous Households," Quarterly Journal of Economics, 95, 375-382.

[2] Becker, Robert and John Boyd (1997), Capital Theory, Equilibrium Analysis and Recursive Utility, Blackwell Publishing Co. Malden, MA.

[3] Brock, William and A.G. Malliaris (1989), Differential Equations, Stability and Chaos in Dynamic Economics, North-Holland, Amsterdam.

[4] Chang, Fwu-Ranq (1988), "Inverse Optimal Problem: A Dynamic Programming Approach," Econometrica, 56(1), 147-172.

[5] Chang, Fwu-Ranq (1994), "Optimal Growth and Recursive Utility," Journal of Optimization Theory and Applications, 80(3), 425-439.

[6] Chang, Fwu-Ranq (2004), Stochastic Optimization in Continuous Time, Cambridge University Press, Cambridge.

[7] Das, Mausumi (2003), "Optimal Growth with Decreasing Marginal Impatience," Journal of Economic Dynamics and Control, 27, 18811898.

[8] Drugeon, Jean-Pierre (1996), "Impatience and Long Run Growth," Journal of Economic Dynamics and Control, 20, 281-313.

[9] Duffie, Darrell and Larry Epstein (1992), "Stochastic Differential Utility," Econometrica, 60, 353-394. 
[10] Epstein, Larry (1983), "Stationary Cardinal Utility and Optimal Growth under Uncertainty," Journal of Economic Theory, 31, 133-152.

[11] Epstein, Larry (1987), "A Simple Dynamic General Equilibrium Model," Journal of Economic Theory, 41, 68-95.

[12] Epstein, Larry and Stanley Zin (1989), "Substitution, Risk Aversion, and the Temporal Behavior of Consumption and Asset Returns: A Theoretical Framework," Econometrica, 57(4), 937-969.

[13] Hicks, John (1965), Capital and Growth, Oxford University Press, Oxford.

[14] Intriligator, Michael, (1971), Mathematical Optimization and Economic Theory, Prentice-Hall, Englewood Cliffs, N.J.

[15] Koopmans, Tjalling (1960), "Stationary Ordinal Utility and Impatience," Econometrica 28, 287-301.

[16] Krylov, N.V. (1980), Controlled Diffusion Processes, Springer-Verlag, New York.

[17] Lucas, Robert E., Jr. and Nancy Stokey (1984), "Optimal Growth with Many Consumers," Journal of Economic Theory, 32, 454-475.

[18] Magill, Michael and Kazuo Nishimura (1984), "Impatience and Accumulation," Journal of Mathematical Analysis and Applications, 98, 270-281.

[19] Uzawa, H. (1968), "Time Preference, the Consumption Function, and Optimum Asset Holdings," in Value, Capital, and Growth: Papers in Honor of Sir John Hicks, N.J. Wolfe (ed.), Edinburgh University Press, Edinburgh, Scotland. 
[20] Wan, Henry, Jr. (1970), Economic Growth, Harcourt Brace Jovanovich, New York. 


\title{
CESifo Working Paper Series
}

\author{
(for full list see www.cesifo.de)
}

1297 David S. Evans and Michael Salinger, An Empirical Analysis of Bundling and Tying: Over-the-Counter Pain Relief and Cold Medicines, October 2004

1298 Gershon Ben-Shakhar, Gary Bornstein, Astrid Hopfensitz and Frans van Winden, Reciprocity and Emotions: Arousal, Self-Reports, and Expectations, October 2004

1299 B. Zorina Khan and Kenneth L. Sokoloff, Institutions and Technological Innovation During Early Economic Growth: Evidence from the Great Inventors of the United States, 1790 - 1930, October 2004

1300 Piero Gottardi and Roberto Serrano, Market Power and Information Revelation in Dynamic Trading, October 2004

1301 Alan V. Deardorff, Who Makes the Rules of Globalization?, October 2004

1302 Sheilagh Ogilvie, The Use and Abuse of Trust: Social Capital and its Deployment by Early Modern Guilds, October 2004

1303 Mario Jametti and Thomas von Ungern-Sternberg, Disaster Insurance or a Disastrous Insurance - Natural Disaster Insurance in France, October 2004

1304 Pieter A. Gautier and José Luis Moraga-González, Strategic Wage Setting and Coordination Frictions with Multiple Applications, October 2004

1305 Julia Darby, Anton Muscatelli and Graeme Roy, Fiscal Federalism, Fiscal Consolidations and Cuts in Central Government Grants: Evidence from an Event Study, October 2004

1306 Michael Waldman, Antitrust Perspectives for Durable-Goods Markets, October 2004

1307 Josef Honerkamp, Stefan Moog and Bernd Raffelhüschen, Earlier or Later: A General Equilibrium Analysis of Bringing Forward an Already Announced Tax Reform, October 2004

1308 M. Hashem Pesaran, A Pair-Wise Approach to Testing for Output and Growth Convergence, October 2004

1309 John Bishop and Ferran Mane, Educational Reform and Disadvantaged Students: Are They Better Off or Worse Off?, October 2004

1310 Alfredo Schclarek, Consumption and Keynesian Fiscal Policy, October 2004

1311 Wolfram F. Richter, Efficiency Effects of Tax Deductions for Work-Related Expenses, October 2004 
1312 Franco Mariuzzo, Patrick Paul Walsh and Ciara Whelan, EU Merger Control in Differentiated Product Industries, October 2004

1313 Kurt Schmidheiny, Income Segregation and Local Progressive Taxation: Empirical Evidence from Switzerland, October 2004

1314 David S. Evans, Andrei Hagiu and Richard Schmalensee, A Survey of the Economic Role of Software Platforms in Computer-Based Industries, October 2004

1315 Frank Riedel and Elmar Wolfstetter, Immediate Demand Reduction in Simultaneous Ascending Bid Auctions, October 2004

1316 Patricia Crifo and Jean-Louis Rullière, Incentives and Anonymity Principle: Crowding Out Toward Users, October 2004

1317 Attila Ambrus and Rossella Argenziano, Network Markets and Consumers Coordination, October 2004

1318 Margarita Katsimi and Thomas Moutos, Monopoly, Inequality and Redistribution Via the Public Provision of Private Goods, October 2004

1319 Jens Josephson and Karl Wärneryd, Long-Run Selection and the Work Ethic, October 2004

1320 Jan K. Brueckner and Oleg Smirnov, Workings of the Melting Pot: Social Networks and the Evolution of Population Attributes, October 2004

1321 Thomas Fuchs and Ludger Wößmann, Computers and Student Learning: Bivariate and Multivariate Evidence on the Availability and Use of Computers at Home and at School, November 2004

1322 Alberto Bisin, Piero Gottardi and Adriano A. Rampini, Managerial Hedging and Portfolio Monitoring, November 2004

1323 Cecilia García-Peñalosa and Jean-François Wen, Redistribution and Occupational Choice in a Schumpeterian Growth Model, November 2004

1324 William Martin and Robert Rowthorn, Will Stability Last?, November 2004

1325 Jianpei Li and Elmar Wolfstetter, Partnership Dissolution, Complementarity, and Investment Incentives, November 2004

1326 Hans Fehr, Sabine Jokisch and Laurence J. Kotlikoff, Fertility, Mortality, and the Developed World's Demographic Transition, November 2004

1327 Adam Elbourne and Jakob de Haan, Asymmetric Monetary Transmission in EMU: The Robustness of VAR Conclusions and Cecchetti's Legal Family Theory, November 2004

1328 Karel-Jan Alsem, Steven Brakman, Lex Hoogduin and Gerard Kuper, The Impact of Newspapers on Consumer Confidence: Does Spin Bias Exist?, November 2004 
1329 Chiona Balfoussia and Mike Wickens, Macroeconomic Sources of Risk in the Term Structure, November 2004

1330 Ludger Wößmann, The Effect Heterogeneity of Central Exams: Evidence from TIMSS, TIMSS-Repeat and PISA, November 2004

1331 M. Hashem Pesaran, Estimation and Inference in Large Heterogeneous Panels with a Multifactor Error Structure, November 2004

1332 Maarten C. W. Janssen, José Luis Moraga-González and Matthijs R. Wildenbeest, A Note on Costly Sequential Search and Oligopoly Pricing, November 2004

1333 Martin Peitz and Patrick Waelbroeck, An Economist's Guide to Digital Music, November 2004

1334 Biswa N. Bhattacharyay and Prabir De, Promotion of Trade, Investment and Infrastructure Development between China and India: The Case of Southwest China and East and Northeast India, November 2004

1335 Lutz Hendricks, Why Does Educational Attainment Differ Across U.S. States?, November 2004

1336 Jay Pil Choi, Antitrust Analysis of Tying Arrangements, November 2004

1337 Rafael Lalive, Jan C. van Ours and Josef Zweimueller, How Changes in Financial Incentives Affect the Duration of Unemployment, November 2004

1338 Robert Woods, Fiscal Stabilisation and EMU, November 2004

1339 Rainald Borck and Matthias Wrede, Political Economy of Commuting Subsidies, November 2004

1340 Marcel Gérard, Combining Dutch Presumptive Capital Income Tax and US Qualified Intermediaries to Set Forth a New System of International Savings Taxation, November 2004

1341 Bruno S. Frey, Simon Luechinger and Alois Stutzer, Calculating Tragedy: Assessing the Costs of Terrorism, November 2004

1342 Johannes Becker and Clemens Fuest, A Backward Looking Measure of the Effective Marginal Tax Burden on Investment, November 2004

1343 Heikki Kauppi, Erkki Koskela and Rune Stenbacka, Equilibrium Unemployment and Capital Intensity Under Product and Labor Market Imperfections, November 2004

1344 Helge Berger and Till Müller, How Should Large and Small Countries Be Represented in a Currency Union?, November 2004

1345 Bruno Jullien, Two-Sided Markets and Electronic Intermediaries, November 2004 
1346 Wolfgang Eggert and Martin Kolmar, Contests with Size Effects, December 2004

1347 Stefan Napel and Mika Widgrén, The Inter-Institutional Distribution of Power in EU Codecision, December 2004

1348 Yin-Wong Cheung and Ulf G. Erlandsson, Exchange Rates and Markov Switching Dynamics, December 2004

1349 Hartmut Egger and Peter Egger, Outsourcing and Trade in a Spatial World, December 2004

1350 Paul Belleflamme and Pierre M. Picard, Piracy and Competition, December 2004

1351 Jon Strand, Public-Good Valuation and Intrafamily Allocation, December 2004

1352 Michael Berlemann, Marcus Dittrich and Gunther Markwardt, The Value of NonBinding Announcements in Public Goods Experiments: Some Theory and Experimental Evidence, December 2004

1353 Camille Cornand and Frank Heinemann, Optimal Degree of Public Information Dissemination, December 2004

1354 Matteo Governatori and Sylvester Eijffinger, Fiscal and Monetary Interaction: The Role of Asymmetries of the Stability and Growth Pact in EMU, December 2004

1355 Fred Ramb and Alfons J. Weichenrieder, Taxes and the Financial Structure of German Inward FDI, December 2004

1356 José Luis Moraga-González and Jean-Marie Viaene, Dumping in Developing and Transition Economies, December 2004

1357 Peter Friedrich, Anita Kaltschütz and Chang Woon Nam, Significance and Determination of Fees for Municipal Finance, December 2004

1358 M. Hashem Pesaran and Paolo Zaffaroni, Model Averaging and Value-at-Risk Based Evaluation of Large Multi Asset Volatility Models for Risk Management, December 2004

1359 Fwu-Ranq Chang, Optimal Growth and Impatience: A Phase Diagram Analysis, December 2004 